REVISTA ANDALUZA DE ANTROPOLOGÍA

NÚMERO 17: ESTRATEGIAS SUBALTERNAS EN AMÉRICA LATINA: RECONFIGURANDO LA IDENTIDAD PARA ARTICULARSE A UN MUNDO GLOBAL. SUBALTERN STRATEGIES IN LATIN AMERICA: RECONFIGURING IDENTITY TO BE ARTICULATED TO THE GLOBAL WORLD.

SEPTIEMBRE DE 2019

ISSN 2174-6796

[pp. 142-145]

http://dx.doi.org/10.12795/RAA.2019.17.08

\title{
ALCARAZ RAMOS, MANUEL (2019). Semanas Santas. Imágenes y palabras de liturgia y tradición. Valencia: Tirant Humanidades.
}

\author{
César Rina Simón \\ Universidad de Extremadura
}

El libro Semanas Santas de Manuel Alcaraz -profesor de Derecho Constitucional en la Universidad de Alicante- tiene especial interés para los investigadores de la religiosidad popular y sus formas rituales, tanto por sus aportaciones al conocimiento de la fiesta como por su fuerza testimonial. No es un ensayo antropológico al uso ni forma parte de la mayoritaria literatura cofradiera positivista que viene perpetuando modelos de comprensión eclesiales y conservadores. Se trata de un conjunto de reflexiones sobre las múltiples dimensiones de la Semana Santa permeadas por recuerdos personales y por su experiencia como visitante, observador y fotógrafo de las celebraciones más señeras de la península. El autor reconoce no haber estudiado de una forma académica el fenómeno, si bien domina las aportaciones realizadas por Isidoro Moreno en la comprensión de los poliédricos significados del rito y maneja bibliografía relevante y andamiajes teóricos bien sustentados.

El libro se compone de varios textos breves ya publicados anteriormente por el autor pero nunca recogidos en un mismo volumen y de una colección muy interesante de fotografías de los ritos en diferentes ciudades, con preeminencia de las Semanas Santas levantinas, seguidas de las andaluzas y castellanas. También ha retratado el rito de Bercianos como hiciera icónicamente Rafael Sanz Lobato en 1970. El álbum fotográfico constata la diversidad y amplitud del fenómeno más allá de Andalucía, donde ha sido más referenciado. Alcaraz menciona tener un archivo personal de más de 15000 fotografías que sería interesante poner a disposición de alguna institución o centro documental para su investigación, ya que suponen un testimonio bastante locuaz del caleidoscopio de la Semana Santa en el cambio de siglo. Las imágenes refuerzan las tesis sostenidas, si 
bien su impresión en el libro es mejorable. Una de las claves de la lectura gráfica es la diferenciación entre dos patrones estéticos e historicistas y dos formas diferenciadas de concebir las celebraciones: el neobarroquismo andaluz y el neomedievalismo castellano, modelos que han determinado también las funciones identitarias de los ritos.

En primer lugar, la obra presenta interés porque ha sido publicada mientras su autor era Conseller de Transparència, Responsabilitat Social, Participació i Cooperació de la Generalitat Valenciana, en representación de Compromís, un partido situado a la izquierda ideológica del PSOE. Es por tanto el primer libro sobre Semana Santa escrito por un activista social de izquierdas en ejercicio de un cargo político de máxima responsabilidad. Esto lo convierte en un testimonio valiosísimo de las complejas y en muchos casos convulsas relaciones políticas con los ritos. Resultado de cuarenta años de dictadura y otros tanto de secuestro interpretativo ortodoxo y conservador de la Semana Santa, puede parecer un oxímoron que alguien de izquierdas muestre su "pasión" por esta celebración. Es probable que la obra no alcance los circuitos editoriales principales ni que se hagan eco los medios de comunicación conservadores, pero no cabe duda de la valentía de Manuel Alcaraz por tratar de quebrar los imagotipos nacionalcatólicos que penden sobre el ritual y que buena parte de la izquierda ha asumido. Como se puede comprobar anualmente cuando se acerca la Semana Santa en diversas declaraciones políticas, una parte significativa de la izquierda ha asumido la idea de que el rito pertenece a la Iglesia y a las derechas o que es una expresión de incultura y de alienación de las clases subalternas. Sin embargo, no siempre fueron hegemónicas estas interpretaciones. Hay una amplia tradición intelectual de izquierdas, progresista o republicana que se ha acercado a estos ritos sin prejuicios supremacistas. Eugenio Noel, Núñez de Herrera, Miguel de Unamuno o Chaves Nogales, los principales narradores de las fiesta en el primer tercio del siglo XX, mostraron que era compatible el republicanismo y el sindicalismo con la participación en fiestas que, si bien cuentan con continentes religiosos, sus significantes los desbordan con creces. Fruto de la recuperación de Gramsci y su teoría de los combates hegemónicos en torno a la cultura popular, ciertos sectores del marxismo -E. P. Thompson, Raymond Williams o Pierre Paolo Pasolini- comenzaron a interpretar estas celebraciones también como oportunidades para la rebeldía festiva. En el terreno de los estudios antropológicos, Isidoro Moreno a partir de los años setenta relacionó la Semana Santa con las estructuras sociales y evidenció los usos políticos a los que se había visto sometida. Su estela fue continuada por varios antropólogos y sociólogos andaluces en la década de los ochenta y noventa, pero la temática perdió interés en el cambio de siglo, al menos desde la perspectiva académica, no así entre las narrativas ortodoxas, que han visto multiplicada su producción y sus nichos de lectores al cobijo de la proliferación de programas televisivos y radiofónicos cofradieros. La temática ha sido recuperada recientemente por algunos investigadores de la dictadura franquista, que han incluido la religiosidad popular como uno de los factores fundamentales en la construcción de la legitimidad 
y el consenso franquista. Semanas Santas, por lo tanto, viene a actualizar una línea interpretativa necesitada de nuevas aportaciones que expliquen el fenómeno en la era de internet. Ésta ha acelerado la globalización del ritual hispalense, cuyas formas, estéticas y significaciones han colonizado buena parte de las Semanas Santas de España. Y es que la celebración no es un fósil del pasado. En las últimas décadas se han experimentado profundas transformaciones en los imaginarios sociales que hacen necesario revisitar conceptos. El trabajo de Manuel Alcaraz podría ser un acicate para un trabajo colectivo y multidisciplinar de las significaciones contemporáneas del rito. En este sentido, el autor hace hincapié acertadamente en la modernidad de unas manifestaciones cuyos anclajes históricos tienen más que ver con la invención de tradiciones y con el gusto moderno por las formas del pasado. Una de las claves de la modernidad fue su actitud arcaizante, su esfuerzo por anclar en el pasado lo novedoso.

Manuel Alcaraz se pregunta en uno de los capítulos si te puede gustar la Semana Santa si eres de izquierdas. La respuesta es sí, incluso desde la no creencia, ya que estos ritos trascienden del fenómeno religioso, lo cual se puede constatar en la coincidencia del auge cofradiero con el vaciamiento de las iglesias y los avances del laicismo. Alcaraz se justifica en que se trata de una fiesta de organización democrática cuyo estallido más potente se vivió durante la transición. De hecho, la peor crisis se vivió durante el tardofranquismo por la disminución drástica de público y cofrades en unos horizontes sociales que identificaban la fiesta con el régimen. La resignificación de la Semana Santa durante la Transición en un requiebro asombroso de apropiación de lo popular en clave identitaria aún no ha sido abordada con profundidad, si bien Alcaraz aporta algunas explicaciones.

Tampoco conviene olvidar que la Semana Santa ha sido, al mismo tiempo, espacio liminar para la rebeldía y para que determinados grupos se visibilicen -Alcaraz apunta certeramente al fenómeno del neobarroquismo gay del horizonte queer-, y escenario de legitimación de las élites y de construcción de consensos gracias al potencial performativo, colectivo y metafórico del ritual. Históricamente, las dos pulsiones han pugnado por apropiarse de la celebración con resultados diferentes en cada contexto, de ahí que la Iglesia trate de reconducirla al templo y no ceje en su empeño de evangelizar a los cofrades.

Resulta también relevante que el autor se haya decantado por un título en plural, apuesta que venimos defendiendo desde diferentes ámbitos, pues al pluralizar el término damos cabida a las infinitas actitudes y formas de concebir los ritos y contribuimos a la ruptura de explicaciones unidireccionales y esquemáticas. Es tal la diversidad del fenómeno, la suma de significantes, funcionalidades y narrativas históricas -románticas, regionalistas, nacionalcatólicas, neobarrocas, autonomistas, etc.- que está justificado su abordaje desde la pluralidad terminológica. 
La relación de los ritos con la subjetivación del espacio urbano ocupa otro capítulo "Semanas Santas, ciudades santas." - Las procesiones dotan de memoria las calles del centro de ciudades cada vez más despobladas por el avance de la gentrificación y colonizadas por cadenas de comida rápida y tiendas de souvenirs. También es importante la ocupación del espacio por parte de hermandades de arrabales y barrios periféricos, cuya procesión a los centros de poder urbano supone una conquista simbólica sólo tolerada en el marco de la fiesta. En otro capítulo, Alcaraz interpreta la Semana Santa en clave de espectáculo moderno, como ya advierta Blanco Withe a comienzos del siglo XIX, cuando señaló que las ciudades habían hecho de las procesiones las fiestas sustitutivas del carnaval y se habían convertido en el teatro popular urbano.

El olfato antropológico del autor justifica el interés de Semanas Santas para los estudios sociales del fenómeno y para todos aquellos investigadores de las fronteras permeables de las culturas políticas españolas, así como una oportunidad para la izquierda de replantear su posición ante los ritos. Como ya advirtiera Gramsci, la hegemonía conservadora sólo se puede explicar desde el abandono de la izquierda de los espacios de la cultura popular. Semanas Santas es, en definitiva, un ejercicio intelectual muy sugerente para enfrentarse a los prejuicios y para despertar un nuevo interés analítico por unas fiestas que cada día alcanzan más influencia en las políticas locales y, por extensión, en los mecanismos de legitimación en comunidades que perciben la ciudad, la política o lo sagrado a partir de su celebración. 